\title{
FRENCH ASSOCIATION FOR THE ADVANCEMENT OF SCIENCE
}

\section{Liege Meeting}

IN response to the kind invitation of the University of Liège, the French Association for the Advancement of Science met during July 17-22 for the third time in Belgium; the previous meetings were at Liège in 1924 and at Brussels in 1932.

The International Water Exhibition at Liège which marked the inauguration of the Albert Canal gave the meeting a special interest. Prof. C. Fabry, president of the French Association, presided over the meeting, and Prof. Dehalu, administrateur. inspecteur of the University of Liège, was president of the local committee.

The opening ceremony took place on July 17 in the hall of the University. Prof. Dehalu expressed his pleasure at receiving the Association at Liège for the second time, and Senator Buisseret, speaking on behalf of the burgomaster, weleomed the members of the congress. Prof. C. D. Ellis, Wheatstone professor of physics at King's College, London, representing the British Association, and Dr. C. Romaña, representing the Argentine Association for the Advancement of Science, brought messages of good will for the success of the meeting. Prof. Fabry, after having expressed the thanks of the Association to the local committeo at Liège, delivered his presidential address, on interstellar space.

Prof. Fabry showed how a profound study of the light of the stars has enabled us to detect, in interstellar space, matter in a state of extremo rarefaction ( $1 \mathrm{kgm}$. nearly in a volume equal to that of the earth). In addition to matter, there exists also in interstellar space energy in the form of radiation emitted by the stars. These results have demonstrated the fruitfulness of collaboration of diverse scientific disciplines and of pure and applied science. Such collaboration is also the object of the French Association and of similar bodies.

The scientific meetings were held in the magnificent Institutes of Civil Engineering and Chemistry of the University of Liège at Val Benoit on July 17 and the following days. July 19 was devoted to an excursion on the Albert Canal and to a visit to a colliery at Beeringen. July 21, the day of the national fête of Belgium, was taken up with a visit to the Water Exhibition.

The several sections of the Association showed great activity. The question of water occupied a prominent place in the programme, and was the subject of the following papers: M. Wyart, the states of solid and liquid water studied by X-rays; II. Cabannes, the Raman spectrum of liquid water; M. I Kraft de la Saulx, history of the construction of hydraulic machines ; M. Tongas, thermodynamic properties of steam ; M. Trochon, microphysics of mists considered as aerosols ; M. Roulleau, hygrometry ; M. Rocard, kinetic theory of liquids; M. Hubault, pollution of waters, their industrial utilization and modifications of their fauna.

The Section of Civil and Military Engineering, under the presidency of M. Campus, was divided into three subsections : theoretical and applied hydraulies; navigable channels and ports; hydraulic works. One session was devoted to colonial hydrography.

The Section of Physics heard communications, among others, from Profs. F. Joliot and F. Perrin. The work of the Section of Geology was completed by field excursions; the Section of Botany also had excursions in which the Royal Society of Botany of Belgium and the Liègo Botanical Circle joined.

The Sections of Biogeography and of Zoology held several joint sessions, with papers on the biology of equatorial lakes (II. Damas), the relations between the internal and external media in aquatic animals (M. Florkin), and the phreatic fauna (MI. R. Leruth).

Mention should also be made of the communications presented to the Section of Geography (streams, their utilization and management, demographic and social aspects of water); and to the Sections of Medical Sciences (metabolism of water), of Psychology and Pedagogy, of Radiology and of Odontology.

Special subsections considered technical applications of water, applications of electricity, archæology and folklore.

The communications presented at the meeting will form a special volume published in connexion with the Liège meeting.

The French Association will meet in 1940 at Nice, some time in July, under the presidency of Prof. Pieron, professor at the Collège de France, and director of the Institute of Psychology of the Univer. sity of Paris.

\section{SOCIAL AND INTERNATIONAL RELATIONS OF SCIENCE}

$\mathrm{T}$ HE first annual report of the Division for the Social and International Relations of Science of the British Association, founded by resolution of the General Committee of the Association in August 1938, was presented at Dundee and is printed with the Report of Council of the Association.

A statement of the aims and objects of the Division, together with a request for information on any work in the field of social relations of science, was circulated to some three hundred and fifty associations, institutions and learned societies in the British Isles and abroad. The replies received indicated that much work of this nature has been done, or is in progress, and in certain instances opportunity has already been found for the Division to exercise its function of co-ordination. Many offers of co-operation were received from bodies particularly interested in the social impacts of science, and several valuable 